\title{
First report of leaf spot disease on sugarcane caused by Bipolaris spicifera in China
}

\author{
Shan Hai Lin • Cheng Hua Huang • Zhan Yun Deng • \\ Mei Xin Yan • Wei Hua Huang • Jin Ju Wei • \\ Zhen Qiang Qin
}

Received: 27 September 2011 / Accepted: 22 February 2012 / Published online: 14 March 2012

(C) Australasian Plant Pathology Society Inc. 2012

\begin{abstract}
A new leaf spot disease of sugarcane caused by Bipolaris spicifera was found for the first time at Luoman town of Liuzhou city, Guangxi Zhuang Autonomous Region, China in 2011. Three pathogenic isolates were obtained and their pathogenicity was confirmed respectively. The pathogenic isolates were identified as $B$. spicifera based on conidial morphology and rDNA-ITS (internal transcribed spacer) sequences comparison. This is the first report of B. spicifera causing leaf spot on sugarcane in China.
\end{abstract}

Keywords Sugarcane $\cdot$ Leaf spot disease $\cdot$ Bipolaris spicifera

S. H. Lin $\cdot$ C. H. Huang $(\bowtie) \cdot$ Z. Y. Deng $\cdot$ M. X. Yan $•$

W. H. Huang $\cdot$ J. J. Wei $\cdot$ Z. Q. Qin

Sugarcane Research Center,

Chinese Academy of Agricultural Sciences,

Nanning 530007, People's Republic of China

e-mail: chenghuahuang@sina.com

S. H. Lin • C. H. Huang • Z. Y. Deng • M. X. Yan • W. H. Huang •

J. J. Wei · Z. Q. Qin

Sugarcane Research Institute,

Guangxi Academy of Agricultural Sciences,

Nanning 530007, People's Republic of China

S. H. Lin • C. H. Huang • Z. Y. Deng • M. X. Yan • W. H. Huang •

J. J. Wei Z. Q. Qin

Key Laboratory of Sugarcane Biotechnology and Genetic

Improvement (Guangxi), Ministry of Agriculture,

Nanning 530007, People's Republic of China
China is the 3rd largest sugarcane (Saccharum officinarum L.) producing country following Brazil and India. For the climatic conditions, major sugarcane producing areas distribute in the south of China, including Guangxi, Yunnan, Guangdong, Hainan and Fujian provinces. Approximately $60 \%$ of the total cane yield is produced in Guangxi ( $\mathrm{Li}$ 2005). Diseases are considered to be the most severe threat to sugarcane production in Guangxi, especially smut, ratoon stunting and viral diseases. Recently, a new leaf spot disease was found on sugarcane in a field at Luoman town of Liuzhou city, Guangxi province in 2011.

The symptoms on sugarcane cultivar GT 21 firstly appeared as a small brown-red water-soaked spot (Fig. 1). Subsequently the diseased areas turned into a black/brown elliptical or fusiform lesion with the central part being grey to brown, while the periphery of the lesion remained brownred. Brown concentric rings were frequently observed on a fully-developed lesion (Fig. 2). The symptoms on the upper and lower leaf surfaces were similar. The disease occurred mainly on the middle and lower node leaves of sugarcane in the field. Three fungal isolates (L1, L2 and L3) were obtained from the leaves with typical symptoms and the pathogenicity of each isolate to sugarcane leaves was confirmed by artificial inoculation tests based on Koch's postulates. Colonies cultured on potato dextrose agar (PDA) were brown to black, circular, woolly or cottony, and abundant conidia were produced. Conidiophores were solitary or in small fascicles, flexuous, geniculate with well developed conidial scars, brown to black, measuring 31.0-510.0 $\times$ 


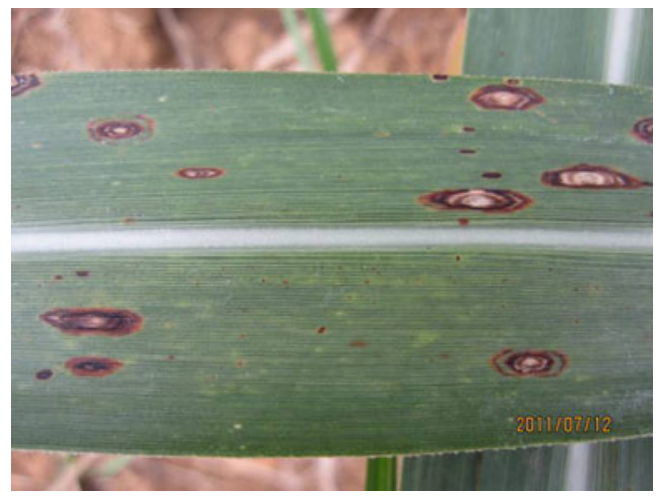

Fig. 1 The primary symptoms of sugarcane leaf spot caused by Bipolaris spicifera in the field

3.5-7.5 $\mu \mathrm{m}$. Conidia were cylindrical, rounded at both ends, brown, smooth, 2-4 (typically 3 ) septate, bipolar-germinating, measuring 14.0-30.0 $\times 6.5-12.0 \mu \mathrm{m}$ (average $23.0 \times 9.2 \mu \mathrm{m}$ ) (Figs. 3, 4). Total genomic DNA samples of the three isolates were extracted using the CTAB method (Lin et al. 2011). The rDNA-ITS sequences of the isolates were amplified with universal primers (ITS1: 5'-TCCGTAGGTGAACCTGCGG -3' and ITS4: 5'-TCCTCCGCTTATTGATATGC-3'). The nucleotide sequences of the isolates shared $99-100 \%$ maximal identity with those of the GenBank-derived B. spicifera isolates. Nucleotide sequences of the isolates were submitted to the GenBank database with the accession

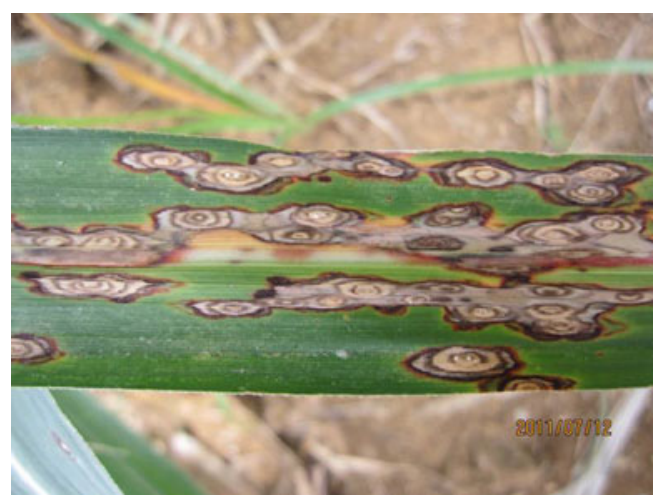

Fig. 2 Typical symptoms of sugarcane leaf spot caused by Bipolaris spicifera in the field

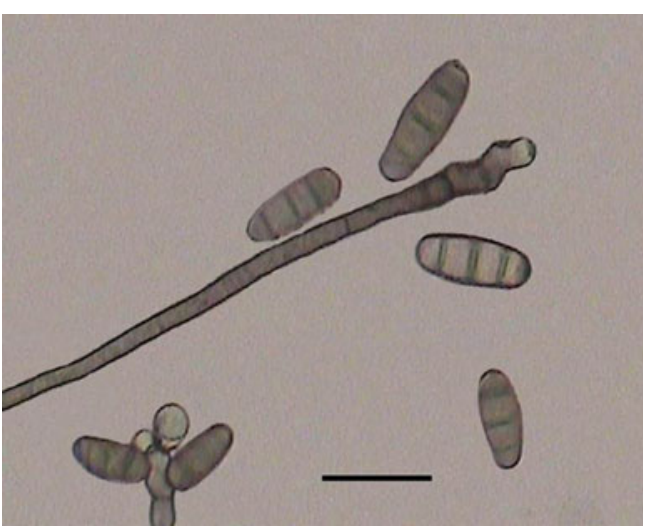

Fig. 3 Conidia and conidiophore of Bipolaris spicifera isolated from an infected leaf of sugarcane $(\mathrm{bar}=20 \mu \mathrm{m})$

numbers of JN695634, JN695635 and JN695636 for isolates L1, L2 and L3, respectively. Culture plates of the isolates were deposited in the China General Microbiological Culture Collection Center in Beijing, China, with the collection numbers of CGMCC 3.14921, CGMCC 3.14922 and CGMCC 3.14923 for isolates L1, L2 and $\mathrm{L} 3$, respectively. The isolates were identified as B. spicifera based on the morphological characters of conidia as well as rDNA-ITS sequences.

B. sacchari, B. stenospila and B. hawaiiensis have been reported as pathogens causing leaf spot diseases on

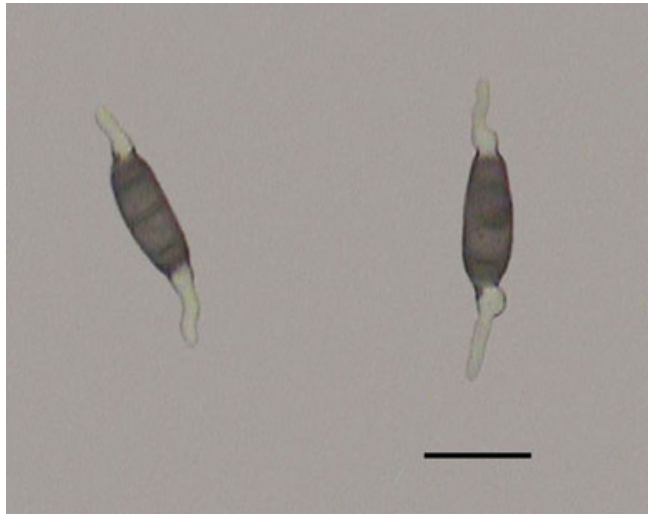

Fig. 4 Bipolar-germinating conidia of Bipolaris spicifera $(\mathrm{bar}=20 \mu \mathrm{m})$ 
sugarcane (Rott et al. 2000). B. spicifera has been reported causing seedling blight of sugarcane in Algeria (Narendra et al. 1978), no report has shown that the pathogen can also cause leaf spot disease on sugarcane. This is the first report of $B$. spicifera causing leaf spot disease on sugarcane.

Acknowledgements This study has been financed in part by grants from the fund of China Agriculture Research System (CARS-20-2-3), Agricultural Public Welfare Research Item (200903004) and Earmarked Fund for Modern Agro-industry Technology Research System (NYCYTXGXCXTD-02).

\section{References}

Li YR (2005) Heralding a new era for sugar industry in China: post IS2004 scenario. Sugar Tech 7(1):1-3

Lin SH, Huang SL, Li QQ, Hu CJ, Fu G, Qin LP, Ma YF, Xie L, Cen ZL, Yan WH (2011) Characterization of Exserohilum rostratum, a new causal agent of banana leaf spot disease in China. Australas Plant Pathol 40(3):246-259

Narendra DV, D'urs S, Setty MVN (1978) Seedling blight of sugarcane -A new disease caused by Drechslera state of Cochliobolus spicifer. Proceedings of the Indian Academy of Science, 87B (Animal Sciences): 45-50.

Rott P, Bailey RA, Comstock JC, Croft BJ, Saumtally AS (eds) (2000) A guide to sugarcane diseases. CIRAD/ISSCT, Montpellier, p 340 